\title{
Stimulating Motivation in L2 Learning in Internet Plus Environment
}

\author{
Wen Lu ${ }^{1, ~ a ~}$, Zeng Ruiyun ${ }^{2, b}$ \\ ${ }^{1}$ College of Foreign Studies, Guilin University of Electronic Technology, Guilin, Guangxi, China \\ ${ }^{2}$ College of Foreign Studies, Guilin University of Electronic Technology, Guilin, Guangxi, China \\ aemail:10810489@qq.com, bemail: ruiyun20@guet.edu.cn
}

Keywords: motivation; second language; fragment; Internet plus

\begin{abstract}
In view of the current weak motivation in English learning, this paper clarifies three concepts, including Internet plus, Internet plus education and Internet plus foreign language education. Four main problems will weak students' motivation in learning English, such as losing enthusiasm in the traditional study, overweight on platform construction, too much time on online entertainment, and fragmental study time. To solve these problems, this paper put forward three strategies including setting a long-term goal, enhancing cross culture input, and making online learning systematically.
\end{abstract}

\section{Introduction}

Motivation is commonly thought of as an inner drive, impulse, emotion, or desire that moves one to a particular action. According to different people, there are different ways to express the definition of motivation. Keller(1983) ${ }^{[1]}$ defines motivation as the choices people make as to what experiences or goals they will approach or avoid and the degree of effort they will exert in that respect. Gardner $(1985)^{[2]}$ defines motivation as the extent to which an individual works or strives to learn because of a desire to do so and the satisfaction experienced in this activity. When motivation is applied to a learning situation, Dörnyei $(2001)^{[3]}$ considers it as "it is related to one of the most basic aspects of the human mind, and most teachers and researchers would agree that it has a very important role in determining success or failure in any learning situation.” In this article, we hold that motivation is a kind of driven force, which refers to individual's intention, willing and psychosocial need to reach the target.

In the Second Language (L2) learning as in every other field of human learning, motivation is the crucial force that determines whether a learner embarks on a task at all, how much energy he devotes to it, and how long he perseveres. It is a complex phenomenon and includes many components, such as curiosities, passing the examinations, learning the different cultures, etc. As for the motivation of foreign language learning, Gardner (1985) ${ }^{[4]}$, pioneer of study foreign language learning motivation, puts forward that motivation includes learning objectives, hardworking, wish for accomplishing the goals and the positive attitudes of language learning. Dörnyei \& Ushioda (2011) ${ }^{[5]}$ considers motivation, a key element in second language (L2) learning, as a person's willingness to engage in an action, make effort, and persist in achieving this action.

In focusing on the reasons why people choose to act in certain ways, it becomes apparent that these reasons for our actions fall into different types. The most common classification of motivation is divided as intrinsic motivation and extrinsic motivation. The degree to which learners are intrinsically or extrinsically motivated to succeed in a task is considered to be the most powerful dimension of the whole motivation construct. Extrinsic motivation comes from the desire to get a reward or avoid a punishment, and the focus is on something external to the learning activity itself. With intrinsic motivation the learning experience is its own reward: 'Intrinsic motivation is evidence whenever students' natural curiosity and interest energize their learning. ${ }^{,[6]}$ Edward Deci considers that intrinsically motivated behaviors are aimed at bringing about certain internally rewarding consequences, namely, feelings of competence and self-determination. ${ }^{[7]}$ 


\section{Some concepts about Internet plus}

\subsection{Internet plus}

The new concept of Internet plus (or Internet+) as a national strategy was put forward by Li Keqiang, the Prime Minister, in the government work report in 2015, which states that the strategy of Internet plus is making the use of Internet platform and information technology to create a new kind of ecology by combining the Internet and all walks of life together. In December the same year, in the Second World Assembly of Internet, Chairman of the Xi Jinping stated that China would vigorously implement the strategy of network power, national strategy of big data, "Internet +" plan of action. From then on, "Internet + " has become an important force to stimulate economy and rapid development of society.

However, it is a new platform for new technologies, which enables the traditional industry to be deeply integrated with the modern Internet instead of simply a relationship between $1+1=2$. In recent years, the Internet plus has deeply changed the form of all walks of life, leading to a series of sub areas, such Internet plus finance, Internet plus communication, Internet plus traffic, Internet plus education and so on.

\subsection{Internet plus education}

Internet plus education is an important part of the national strategy of Internet plus. It is the pioneer and new sharp of education reform and development, which is a powerful engine to speed up the modernization process of education. Some people believe that Internet plus education is the application of Internet technology to education, so that education teaching results are more effective and the quality resource allocation is more balanced. Some consider it as a new type of education form by the use of network technology, multimedia technology and other modern technologies, which is based on modern education of electronic information and communication technology. ${ }^{[8]}$ In this article, we recon Internet plus education as a deep integration of the Internet with traditional education teaching by using information communication technology and Internet platform, which means that it is the equivalent of adding a pair of "Internet" wings to traditional education, making the traditional education teaching to develop fast. Internet plus education has the following five characteristics, including crossover connection, innovation driven, optimize relation, expand openness and more ecological performances.

\subsection{Internet plus foreign language education}

In the background of Internet plus and the great age of the education informationization, Internet has enhanced the level of college English teaching and promoted college English teaching reform. Today when we're talking about the deep fusion of information technology and English class, the innovation and development, the word data is mentioned and discussed repeatedly. The meaning of digital resources is very special, which is easy to create a true, rich language environment for English learners, and makes the classroom teaching of the virtual and real language use organic fusion of learning foreign language, therefore, expanding the language input for English learners, and increasing the capacity of teaching and improving teaching depth. A large number of course learning platforms, APPs and webs came to people's life, such as Mooc platform, whose common characteristic considers university curriculum construction as the main body. In this article, we take English as second language. Facing the new international condition, it is a serious task for higher education to cultivate the international foreign talents qualifying the international standard and strong comprehensive quality.

\section{Problems in English learning in the Internet plus environment}

With the rapid development of information technology, college English teaching has become inseparable from modern information technology. Whether it is popular now for class, for example, Moocs, micro class or flip classrooms, they are changing our traditional teaching idea, and at the 
same time it is also a new challenge for college English. Generally speaking, there are four main problems concerning about the Chinese students learning English at the age of Internet plus education.

First, students lose enthusiasm to the traditional study. The basic characteristics of traditional education put emphasis on imparting knowledge by too much focus on the role of the teacher, thus curbing the students' individuality and creativity and ignoring students' initiative and potential of the play. However, it is very convenient for the students to get something he wants from the Internet now. They do not need to remember and rotate too much information. If they come across some problems, they will search the Internet to find the answers instead of thinking it over independently. They keep actively in the Internet, and a great part of the students lose their interest in the traditional classes. In fact, it is the instrumental motivation which leads the students do not focus on study after the examination. They are eager for quick success and instant benefits. What's more, the text books cannot attract students' attention as the Internet does. Some students consider it is boring to sit in the classroom to listen to the teachers. At present, generally speaking, there are about 60 students in one class, or some classes may contain more than 100 students. Their English abilities differ greatly. So it is so difficult for teachers to get all the students' attention in the class.

Second, universities attach more importance to online construction than application. In 2014, the Ministry of Education issued to build an effective mechanism of an implementation plan by informationization means to expand the coverage of high quality education resources. So cloud platform construction is a climax all over the country. But until now, there is not a landmark cloud platform which is widely recognized, and instead, a large number of platforms had been constructed fragmentally and in a state of chaos. Most cloud platforms are far from connected, losing to keep pace with the age of the Internet education development. For many years, the problem of highlighting on construction instead of application has not solved, which is a barrier in the development of Internet education. For example, there are a dozen of platforms in a school, and a teacher has dozens of accounts. However, in fact, both the teachers and students do not use these platforms. What' more, there is no breakthrough in the education resource platform constructions. Inundation of resources, good and bad mixed together, different standards, lack of integration, etc. are very common, and they have a poor quality and make little sense to students and therefore, students' motivation in learning English becomes weak.

Third, the Internet entertainments dominate the students' cultural life. As college students are the main body of campus culture construction, creating an active, upward and rich cultural atmosphere is conducive to the healthy development of students' body and mind. Online entertainment dominates college students' spare time, such as online music, online movie series, network community, network BBS, portal layout of entertainment, online games and so on, which exerts a subtle influence on students' way of thinking, behavior patterns, values, and so on. College students are full of curiosity and thirst for knowledge, so they like to pursue new things, to show their individuality, to accept new things and new ideas easily. According to a survey by Zhimei-HUANG et $\mathrm{al}^{[9]}$, for entertainment, 91.5 percent of students preferred online entertainments, which means that the most popular form of entertainment for college students is online entertainment and $82.1 \%$ of them spend two to five hours online, some even longer. They can surf the Internet anytime and anywhere, and they are very dependent on the Internet. Along with the popularization of network, college students have a special emotion to the network. On the one hand, the network as instrumental meaning makes they have different life and study way from their parents; on the other hand, the long-time contact with the Internet will inevitably produce psychological and emotional dependency. In a word, network game is multifarious, college students is at a stage of increasingly maturing ideological values, their world view and judgment of things is not adequate for them to distinguish wrong and right, thus they are very vulnerable to erode by the unhealthy content and way of Internet, leading to a lot of time spent on Internet entertainment than study.

Fourth, students' study time is fragmented. The fragmentation of learning time is the characteristic of the Internet, and it is the modern life style formed by the development of mobile Internet technology. For online education, fragmented learning is the foundation of the existence of Internet. 
If only the limitation of space distance and learning time is solved, but no follow by the trend of fragmentation learning, then online education will always become useless. It is difficult to select useful knowledge in the ocean of mixed information avoiding wasting students' study time and energy. And it is not easy to ensure the depth of learning which is hard to guarantee if students don't string together these scattered knowledge points into their own knowledge system. In the process of fragmentation learning, your knowledge will form a scatter diagram in an EXCEL diagram that is not connected to a network and is not a system. Fragmented knowledge is highly targeted, but lacks environmental adaptability. We always receive fragmentation knowledge, often encountering shortcut or tips, etc., which can let us receive these "new knowledge" blindly, without deep thinking about. Fragmented knowledge makes it easy to lose the habit of thinking. By learning these fragmentation knowledges, some summary of a problem or phenomenon, it is easy to make them to be addicted to Internet and lose the habit of thinking.

\section{Strategies to stimulate students' motivation}

It is important to stimulate students' motivation because it is crucial in the process of education. The more the learners feel that they are gaining from the language, the more motivated they are likely to be, and vice versa. The ultimate aim of any second language learning should be to make learners feel that if they do not study, they will have missed something that would have been of value to them. So we want to stimulate students' motivation from both intrinsic and extrinsic ways.

First, helping students to set long-term goals to cultivate the intrinsic learning motivation is crucial. We should stress on the importance of making the students are clear about their studying goals. The Internet can only provide us about the raw materials of solving some problems. Actually, what they need to do is to apply the knowledge flexibly. Instead of only finding answers in the Internet, they can explore the varieties of English culture. As long as they find it is a happy thing to learn English, they can improve their English. Encouraging themselves to practice more can make them find the accomplishments and confidence. Chomsky considers the importance of activating learners' motivation as "The truth of the matter is that about 99 percent of teaching is making the students feel interested in the material." [10]

Second, enhancing students' cross cultures input is important. Teachers should make students form the concept that high English proficiency can provide them more opportunities in the future. They will benefit from it in some day, even though they might not be using it for the time being. They can read English history, literature, newspaper, and magazine, watch movies in English version or listen to English songs. All these might enlarge their horizon and contribute to their success in their career. What's more, English can also serve as a means to know about other nations and open a totally different world. If they learn English well they can communicate with foreigners and learn the way they live, behavior, and their concept. It is always exciting to explore the other cultures as so many things new and fascinating. Thanks to Internet, it is important for universities to provide different kinds of resources for the students to finish after class. The resources can be some interesting passages, famous songs, latest news and some videos. Now, it is convenient for nearly all the students to get access to the Internet, and they have much free time as they have limited classes. So in order to make the students get involved to the autonomous learning is crucial. However, teachers should strengthen the supervision and monitor students' study. Teachers should make their study by formative evaluation to make their extrinsic motivation to become intrinsic motivation.

Third, guiding students to learn systematically online means a lot. To solve any problems, we all need to analyze the causes, and then find a solution, but fragmentation knowledge ignores this process, and instead provides a single method to resolve the problem, thus lacks environment adaptability. The fragmentation of knowledge makes people ignore the basics and become obsessed with form. In addition to the systematically learning knowledge, independent thinking and careful analysis, the main thing is that we're going to make fragmentation knowledge to form systematically or put fragmentation knowledge into the current learning system. Therefore, it is important to draw their own knowledge network by holding a pen and paper and drawing on the paper to form their own 
mind map. They also need to modify as well as enrich their own knowledge network constantly, thus gradually they will change the various fragmentation knowledge into the basic knowledge and enrich their own knowledge system, forming their own knowledge system. Simplify the sources of information. There is a lot of good content on the Internet, but it's not useful for them, so choose what they need. It is important not to take information as knowledge, but to choose what is useful to them. The high quality content of each platform becomes the auxiliary of the knowledge system. After streamlining the sources of information, they should insert the effective content of the network into their own knowledge network. The environment matches the learning content. Different environments read different things, such as commuting to school, which is better for reading news.

\section{Conclusions}

Researchers on motivation assert that the greater the motivation, the more successful learners will be in learning the language. In the Internet plus environment, the application of technology of Internet helps language learners begin to practice their English on their own without the restrict of time and place. Keeping perfecting system of education, the motivation of learning English is one of the most important factors in cultivating the international talents. Teachers should combine their classes with Internet information and put emphasis on application of APPs or platforms instead of constructing as many as possible. When students' external motivation to learn English transfers to internal motivation, their English proficiency has improved. In the future, more practical studies on how to stimulate students' motivation will be involved.

\section{Acknowledgements}

This work is supported by Research on the Construction of an Effective Multi-modal English Oral Output Teaching Mode in the Cloud Environment (Grant No. 2016JGB223), Guangxi Higher Education Undergraduate Teaching Reform Project.

\section{References}

[1] J. M. Keller. Motivation Design of Instrument. In C. M. Reigeluth (ed.). Instrumental Design Theories and Models. New Jersey: Erlbaum (1983). P.389.

[2] R.C. Gardner. Social Psychology and Second Language Learning: The Role of Attitudes and Motivation. London: Edward Arnold (1985).

[3] Z. Dörnyei. Motivational Strategies in the Language Classroom. Cambridge, England: Cambridge University Press (2001). P.2.

[4] R. C. Gardner. Social Psychology and Language Learning: The Role of Attitude and Motivation. Edward Arnord, London (1985), p.50.

[5] Z. Dörnyei \& E. Ushioda. Teaching and Researching Motivation (2nd ed.). Harlow: Longman (2011).

[6] J. Arnold. Affect in Language Learning. Foreign language teaching and research press, Beijing (2000), p.14.

[7] H. D. Brown. Principles of Language Learning. Foreign language teaching and research press, Beijing (2002), p.155-156.

[8] W. Lei, Z. Ji. No Boundary: Internet+ Education. Beijing: China Citic Press (2015), p.3-4.

[9] H. Zhimei, W. Yanhong, Y. Yonghua. Study on the Lifestyle of Health Network Entertainment for the Post-90s College Students—a Case Study of Universities in Quanzhou Area. Journal of HuBei TV University, Vol.33 (2013), p.56-57.

[10] J. Arnold. Affect in Language Learning. Foreign language teaching and research press, Beijing (2000), p.13. 